\title{
ELECTROCHEMICAL DETERMINATION OF KETOROLAC - A NON-OPIOID ANALGESIC AT GLASSY CARBON ELECTRODE
}

\author{
ROHINI M HANABARATTI ${ }^{1}$, JAYANT I GOWDA ${ }^{2}$, SURESH M TUWAR ${ }^{1 *}$ \\ ${ }^{1}$ Department of Chemistry, Karnatak Science College, Dharwad, Karnataka, India. ${ }^{2}$ P.G. Department of Chemistry, PC Jabin Science College, \\ Hubballi, Karnataka, India. Email: sm.tuwar@gmail.com \\ Received: 24 September 2018, Revised and Accepted: 17 November 2018
}

\section{ABSTRACT}

Objectives: The study has been carried to investigate the electro-oxidation mechanism and to develop selective and sensitive methods for the determination of a non-opioid analgesic drug ketorolac (KTL).

Methods: A simple method was used for the determination of KTL using a glassy carbon electrode by cyclic and differential pulse voltammetric techniques. The effect of various experimental parameters such as accumulation time, pH, scan rate, on the voltammetric responses of KTL was evaluated.

Results: In the optimized conditions, variation of peak current with respect to concentration was studied and the calibration curve of the peak current versus KTL concentration was drawn with a linear range of $10-350 \mu \mathrm{M}$ and an excellent detection limit of $8.08 \times 10^{-8} \mathrm{M}$. The method was successfully applied for the determination of KTL in pharmaceuticals and human urine samples.

Conclusions: From the results, it has been observed that the selected method is rapid, sensitive, and low cost.

Keywords: Ketorolac, Glassy carbon electrode, Calibration curve, Detection limit, Pharmaceutical analysis.

(c) 2019 The Authors. Published by Innovare Academic Sciences Pvt Ltd. This is an open access article under the CC BY license (http://creativecommons. org/licenses/by/4. 0/) DOI: http://dx.doi.org/10.22159/ajpcr.2019.v12i3.29914

\section{INTRODUCTION}

In the past few decades, electrochemical techniques have been received considerable interest in the detection of small bio-molecules due to their high sensitivity, rapid response, simple operation, and low expense [1].

Ketorolac (KTL, as shown in Scheme 1) is a potent intravenous NSAID and a non-selective cyclo-oxygenase inhibitor which mediates pain, inflammation, and fever [2]. It has been evaluated and used for the treatment of moderate to severe pain including post-operative pain [3].

KTL crosses the placenta and is also excreted into breast milk in small quantities. The hydrophilicity and high protein binding of KTL prevent large concentrations of the drug from entering the breast milk. Administrations of KTL and other NSAIDs during the third trimester are contraindicated because they can cause premature closure of the ductus arteriosus.

A number of analytical methods have been investigated for the determination of KTL either alone or in its salt form or combination with other drugs, such as liquid chromatography-mass spectrometry (LC-MS/MS) [4], high-performance thin-layer chromatography [5], LC-MS [6], and high-performance liquid chromatography (HPLC) [7-11]. KTL has been determined in blood after a solid-phase extraction by gas chromatography-MS after derivatization using diazopropane [12]. Study in human serum has been performed by HPLC [13,14]. A flow injection analysis (FIA) method with spectrophotometric detection after derivatization with dichloronitrophenol in pharmaceutical formulations was published [15].

Most of the reported spectrophotometric methods based on derivative technique have shown poor selectivity, sensitivity, and required additional software's. Although the FIA and gas chromatographic methods have shown high sensitivities, they are expensive, involving the use of complex procedures with several sample manipulations and take longer analysis time. Hence, the development of an effective and efficient method for the determination of KTL in pharmaceutical preparation and biological fluids is an important task. To the best of our knowledge, only a few electrochemical methods have been reported for the determination of KTL in literature. The current study describes the determination of KTL in tablets and spiked human urine samples at glassy carbon electrode (GCE). The proposed method showed many advantages such as low detection limit, fast response, easy to apply, and economical for routine analysis. We believe that the proposed method would be a potential step forward in the determination of KTL in biological fluids.

\section{METHODS}

\section{Reagents and materials}

All chemicals and reagents were of analytical grade and used as received. KTL was purchased from Sigma-Aldrich. $0.2 \mathrm{M}$ phosphate buffer solutions ( $\mathrm{pH}$ 3.0-11.2) were prepared using $\mathrm{H}_{3} \mathrm{PO}_{4}, \mathrm{Na}_{2} \mathrm{HPO}_{4}$, and $\mathrm{NaH}_{2} \mathrm{PO}_{4}$, and double-distilled water was used throughout the experiment.

\section{Instrumentation}

All the voltammetric measurements (cyclic voltammetry and differential pulse voltammetry [DPV]) were carried out on CHI1112C (Version 9.03) using a $10 \mathrm{~mL}$ capacity electrochemical cell with the conventional three-electrode system: A platinum wire as a counter electrode, an $\mathrm{Ag} / \mathrm{AgCl}$ electrode as the reference, and the GCE as working electrode. Solutions of various $\mathrm{pHs}$ were used, adjusted with $\mathrm{H}_{3} \mathrm{PO}_{4}, \mathrm{Na}_{2} \mathrm{HPO}_{4}$, and $\mathrm{NaH}_{2} \mathrm{PO}_{4}$ (different supporting electrolytes were also tested, such as Britton-Robinson buffer and acetate buffer). The $\mathrm{pH}$ of the buffer solution was measured using Elico model EI120 pH meter. All experiments were carried out at an ambient temperature of $25 \pm 0.1^{\circ} \mathrm{C}$. 
Area of the electrode

The area of the electrode was obtained by a cyclic voltammetric method using $1.0 \mathrm{mM} \mathrm{K}_{3} \mathrm{Fe}(\mathrm{CN})_{6}$ as a probe at different scan rates. For a reversible process, the following Randles-Sevcik formula [16] can be used to calculate the area of the electrode:

$$
\mathrm{i}_{\mathrm{pa}}=\left(2.69 \times 10^{-5}\right) \mathrm{n}^{3 / 2} \mathrm{AD}_{0}{ }^{1 / 2} \mathrm{C}_{0 \mathrm{~V}}{ }^{1 / 2}
$$

Where $i_{p a}$ refers to the anodic peak current, $n$ is the number of electrons transferred, $A$ is the surface area of the electrode, $D_{0}$ is diffusion coefficient, $\mathrm{v}$ is the scan rate, and $\mathrm{C}_{0}$ is the concentration of $\mathrm{K}_{3} \mathrm{Fe}(\mathrm{CN})_{6}$. For $1.0 \mathrm{mM} \mathrm{K}_{3} \mathrm{Fe}(\mathrm{CN})_{6}$ in $0.1 \mathrm{M} \mathrm{KCl}$ electrolyte, $\mathrm{n}=1$, $D_{0}=7.6 \times 10^{-6} \mathrm{~cm}^{2} / \mathrm{s}[16]$, then from the slope of the plot of $i_{p a}$ versus $\mathrm{u}^{1 / 2}$, the surface area of the electrode can be calculated. In our experiment, the slope was $14.15 \times 10^{-6} \mu \mathrm{A}\left(\mathrm{Vs}^{-1}\right)^{-1 / 2}$ and the area of electrode was calculated to be $0.0212 \mathrm{~cm}^{2}$.

\section{Analytical procedure}

For good reproducible results, the working electrode was carefully polished with $1 \mu \mathrm{m}, 0.3 \mu \mathrm{m}$, and $0.05 \mu \mathrm{m} \alpha$-alumina on smooth polishing cloth and then washed in double-distilled water. The three electrode systems consisting of a GCE (3 mm diameter) as the working electrode, an $\mathrm{Ag} / \mathrm{AgCl}(3 \mathrm{M} \mathrm{KCl})$ reference electrode, and a platinum wire as the auxiliary (counter) electrodes were used. The experimental conditions for DPV were: Initial potential: $1.1 \mathrm{~V}$, final potential: $1.4 \mathrm{~V}$, sensitivity: $1 \times 10^{-6} \mathrm{~A} / \mathrm{V}$, pulse amplitude: $50 \mathrm{mV}$, sample width: $20 \mathrm{~ms}$, pulse period: $500 \mathrm{~ms}$, and scan rate: $50 \mathrm{mV} / \mathrm{s}$.

\section{Standard and pharmaceutical sample preparation}

The commercially available tablets of KTL were weighed and powdered using pastel mortars. A portion of the powder equivalent to about 1.0 $\mathrm{mM}$ was weighed accurately, transferred to a $100 \mathrm{~mL}$ calibrated flask and completed the volume with double distilled water. It was then sonicated for 15 min to effect complete dissolution and diluted to volume with water. Suitable amounts of this solution were taken and analyzed. The amount of KTL in the tablet was calculated using a calibration graph or regression equation.

To study the accuracy of the proposed method, and to check the interference from excipients used in the dosage forms, recovery experiments were carried out by the standard addition method. This study was performed by addition of known amounts of KTL to a known concentration of the tablets. The resulting mixture was analyzed as in pure KTL.

\section{Determination of KTL in spiked human urine samples}

Using the calibration curve method, the application of the method for the determination of KTL in human urine was also investigated. The urine sample was diluted 100 times with $0.2 \mathrm{M} \mathrm{PBS}(\mathrm{pH}=3.8)$ to fit the calibration curve and reduce the matrix effect. No other pre-treatment process was performed.

\section{ESULTS AND DISCUSSION}

\section{Cyclic voltammetric investigation of KTL}

The voltammetric behavior of KTL was investigated using cyclic voltammetry. Fig. 1 shows typical cyclic voltammograms of $0.1 \mathrm{mM}$ of $\mathrm{KTL}$, in PBS of pH 3.8 at scan rate $50 \mathrm{mV} / \mathrm{s}$ recorded at GCE. This shows two oxidation peaks at $0.982 \mathrm{~V}$ and $1.355 \mathrm{~V}$. On scanning in the negative direction; no reduction peak was observed, showing that the oxidation of KTL is an irreversible process in this potential range. The peak intensity and peak current of the second oxidation peak are maximum, hence, selected the same for the analytical purpose.

\section{Effect of pH}

The electrochemical responses of $0.1 \mathrm{mM}$ KTL at GCE in phosphate buffer of different $\mathrm{pH}$ (3.0-11.2) were investigated, and the corresponding voltammograms are shown in Fig. 2a. It was noticed that the oxidation peak shifted toward negative potentials with an increase in $\mathrm{pH}$ indicating the role of protons in the oxidation process [17]. For pHs comprised between three and seven, two well-defined voltammetric peaks were observed. At $\mathrm{pH}$ above seven these two peaks were fused into only one peak. The evolution of both peak potential and peak current with $\mathrm{pH}$, for both peaks, is shown in Fig. $2 b$ and c. Furthermore, both peaks potential showed a linear dependence with the $\mathrm{pH}$ variation confirms the transfer of electrons and protons during the electrochemical process [18-20]. The equations relating to them can be represented as:

$$
\begin{gathered}
E_{p}=-0.003 p H+1.369\left(R^{2}=0.974\right) \\
E_{p}=-0.003742 p H+0.998251\left(R^{2}=0.985\right)
\end{gathered}
$$

Effect of the time and potential of the accumulation

In the accumulation step, two important parameters are potential and time of accumulation, which can affect the sensitivity of determination via changing the amount of adsorbed KTL at the surface of modified electrode. Hence, influence of these parameters on the peak current was studied by the cyclic voltammetric method. It was found that by increasing the accumulation time, until $50 \mathrm{~s}$, the peak current was increased; due to increasing the amount of the adsorbed analyte and it can be seen that after $50 \mathrm{~s}$, the peak current stays nearly constant.

At the optimum value of accumulation time $(50 \mathrm{~s})$, the effect of accumulation potential was investigated form 0.2 to $-0.2 \mathrm{~V}$. The results showed that changing the potential of accumulation step from open circuit condition has no effect on the peak current. Therefore, $50 \mathrm{~s}$ of accumulation time in an open circuit condition was chosen for the accumulation step in all voltammetric determinations.

\section{Effect of the potential scan rate}

Cyclic voltammetric studies at different potential scan rates $(25-400 \mathrm{mV} / \mathrm{s})$ for $0.1 \mathrm{mM}$ solution of KTL were performed on the surface of GCE in a PBS of pH 3.8 as shown in Fig. 3a. It was found that the peak current has a linear relationship with the square root of scan rate as it is shown in Fig. 3b. This linear relationship confirms the diffusion-controlled process [21] for the electro-oxidation of KTL at the electrode. Further, the plots of $\log \mathrm{I}_{\mathrm{pa}}$ versus $\log v$ gave the slope of 0.39 for peak 1 and 0.31 for peak $2\left(\log I_{\text {pa1 }}=0.391 \log v+1.296 R^{2}=0.943\right.$; $\log$ $\left.\mathrm{I}_{\mathrm{pa} 2}=0.317 \log \mathrm{v}+0.749, \mathrm{R}^{2}=0.969\right)$ confirming the diffusion controlled electrode process $[21,22]$.

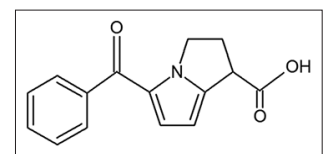

Scheme 1: Chemical structure of ketorolac

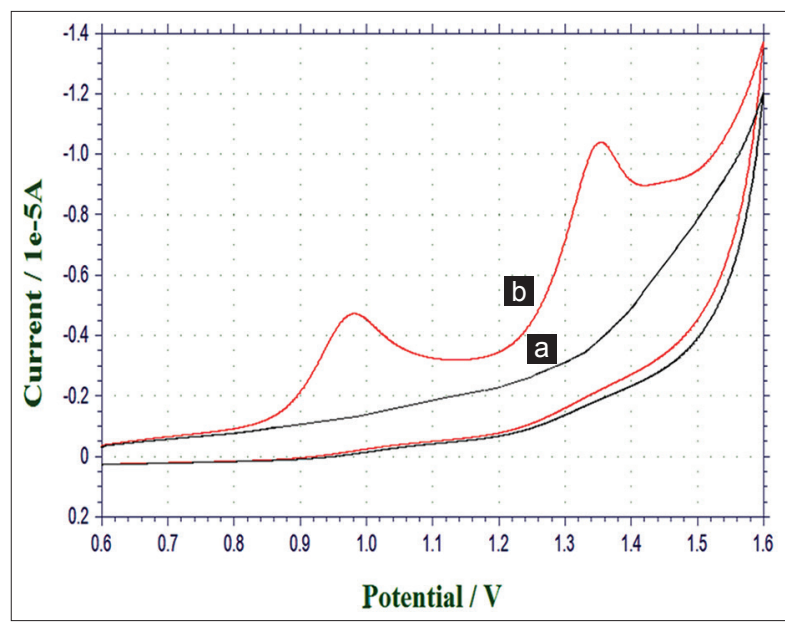

Fig. 1: Cyclic voltammogram of $0.1 \mathrm{mM}$ KTL at (a) bare glassy carbon electrode, (b) glassy carbon electrode + KTL; scan rate $50 \mathrm{mV} / \mathrm{s}$; phosphate buffer of pH 3.8 as supporting electrolyte 


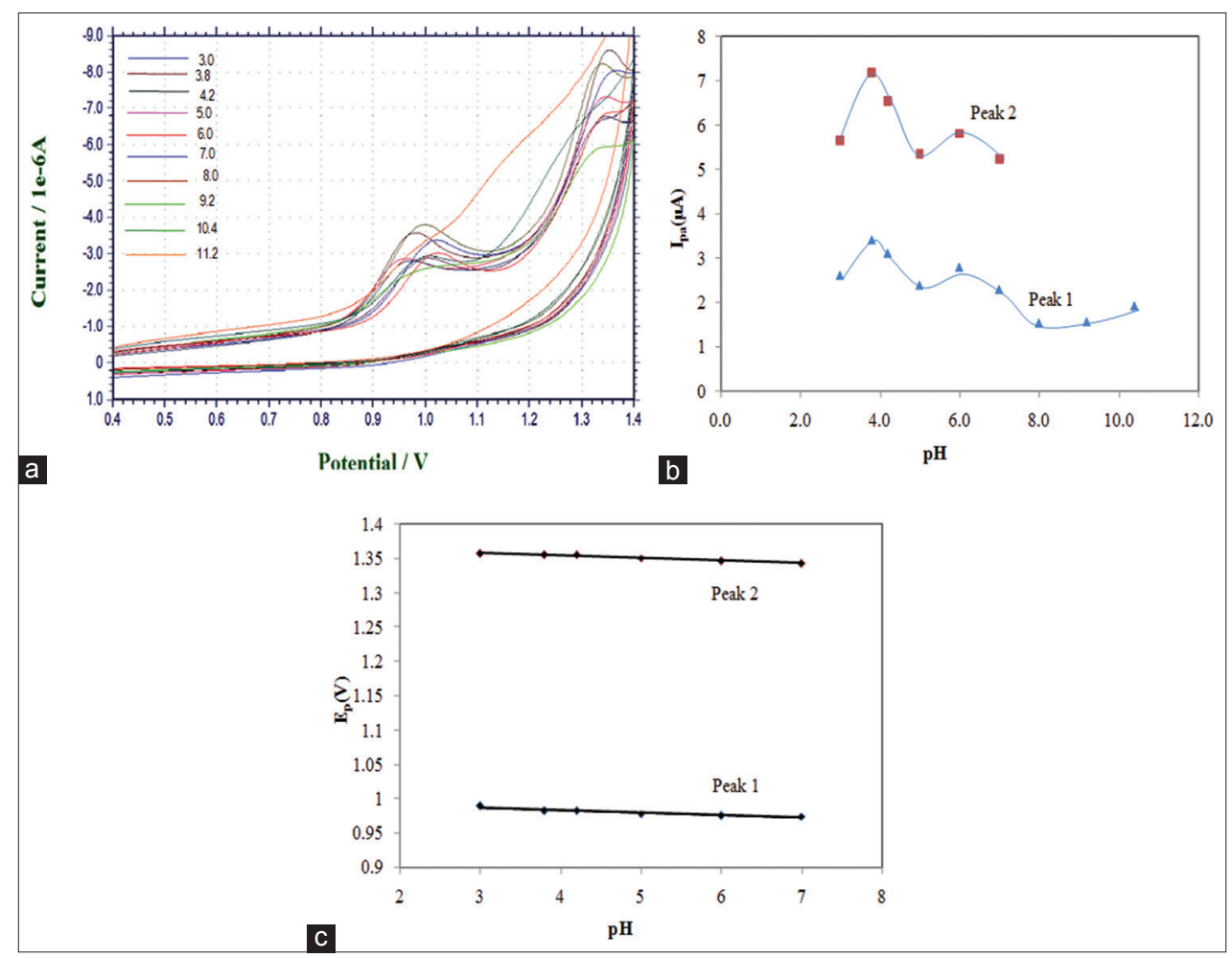

Fig. 2: (a) Influence of $\mathrm{pH}$ on the shape of the anodic peak, pH: 3.0-11.2. (b) Variations of peak currents $\mathrm{I}_{\mathrm{pa}}(\mu \mathrm{A})$ of $\mathrm{KTL}$ with pH. (c) Influence of $\mathrm{pH}$ on the peak potential $\mathrm{E}_{\mathrm{p}}(\mathrm{V})$ of KTL. Other conditions as shown in Fig. 1

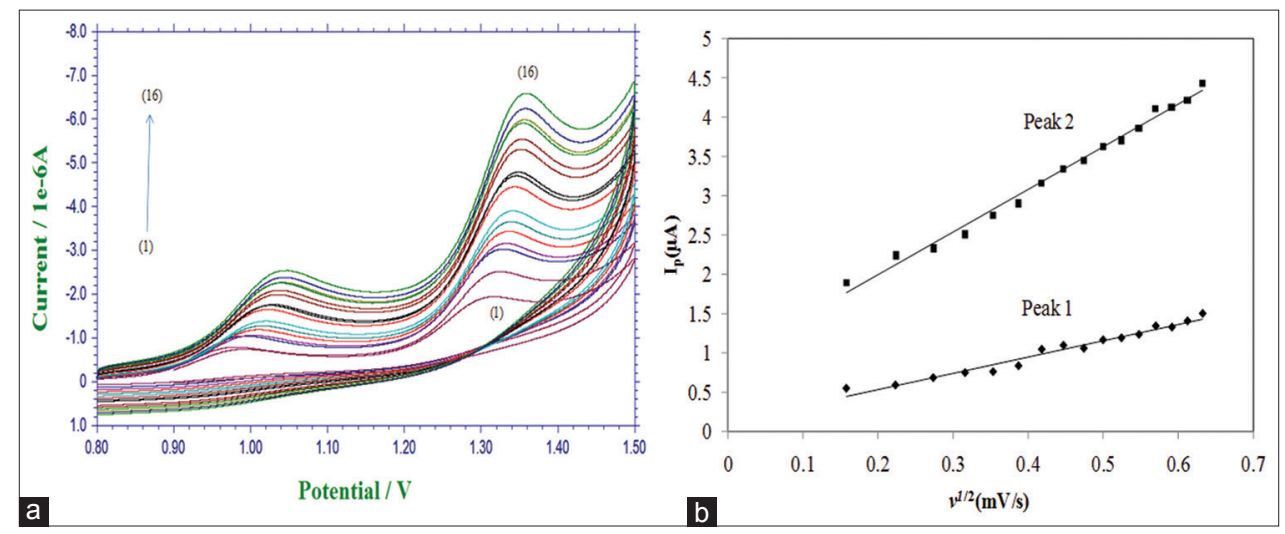

Fig. 3: (a) Cyclic voltammograms for the oxidation of KTL at different scan rates (1)-(16): $25 \mathrm{~m} \mathrm{v} / \mathrm{s}$ - $400 \mathrm{~m}$ v/s. (b) Dependence of oxidation peak current on the square root of scan rate

As for an irreversible electrode process, according to Laviron [23], $\mathrm{E}_{\mathrm{pa}}$ is defined by the following equation:

$$
\mathrm{E}_{\mathrm{pa}}=\mathrm{E}^{0^{\prime}}+\left(\frac{2.303 \mathrm{RT}}{\alpha \mathrm{F}}\right) \log \left(\frac{\overrightarrow{\mathrm{R} T k^{0}}}{\alpha \mathrm{nF}}\right)+\left(\frac{2.303 \mathrm{RT}}{\alpha \mathrm{F}}\right) \log \mathrm{v}
$$

Where $\alpha$ is the transfer coefficient, $\mathrm{k}^{0}$ the standard heterogeneous rate constant of the reaction, $n$ the number of electrons transferred, $v$ the scan rate, and $\mathrm{E}^{0^{\prime}}$ is the formal standard redox potential. Other symbols have their usual meaning. Thus, the value of $\alpha$ can be easily calculated from the slope of $E_{p}$ versus $\log v$ plot. In this system, the slope is 0.054 and 0.030 for peak 1 and peak 2, respectively. Taking $\alpha=0.5$ for irreversible electrode process, $\mathrm{T}=298 \mathrm{~K}, \mathrm{R}=8.314 \mathrm{JK} / \mathrm{mol}$, and $\mathrm{F}=96480 \mathrm{C} / \mathrm{mol}$, the number of electrons (n) transferred in the electrooxidation of KTL was calculated to be 1.24 1.0 and 2.23 2.0 for first and second peak, respectively. The value of $\mathrm{k}^{0}$ can be determined from the intercept of the previous equations, if the value of $\mathrm{E}^{0^{\prime}}$ is known. The
Table 1: Characteristics of KTL calibration plot using differential pulse voltammetry at a glassy carbon electrode

\begin{tabular}{ll}
\hline Linearity range & $10-350 \mu \mathrm{M}$ \\
Slope of the calibration plot & 340.0 \\
Intercept & 3.677 \\
Correlation coefficient (r) & 0.987 \\
RSD of slope (\%) & 0.26 \\
RSD of intercept (\%) & 1.33 \\
Number of data points & 12 \\
LOD (M) & $8.08 \times 10^{-8}$ \\
LOQ (M) & $2.69 \times 10^{-7}$ \\
\hline
\end{tabular}

RSD: Relative standard deviation, LOD: Limit of detection, LOQ: Limit of quantitation

value of $E^{0^{\prime}}$ in eqn. (1) can be obtained from the intercept of $E_{p}$ versus $v$ curve by extrapolating to the vertical axis at $v=0$ [24]. In our system, the intercept for $\mathrm{E}_{\mathrm{p}}$ versus $\log \mathrm{v}$ plot was 1.065 and 1.368 for peak 1 and 
Table 2: Comparison of detection limits for KTL to different classical methods

\begin{tabular}{lll}
\hline Method & LOD & References \\
\hline RP-HPLC method & $3.97 \times 10^{-7} \mathrm{M}(0.116 \mu \mathrm{g} / \mathrm{mL})$ & 8 \\
LC and LC-MS & $7.19 \times 10^{-7} \mathrm{M}(0.21 \mu \mathrm{g} / \mathrm{mL}$ & 28 \\
Spectrophotometric method & $1.18 \times 10^{-7} \mathrm{M}$ & 25 \\
Differential pulse polarographic determination & $4.04 \times 10^{-6} \mathrm{M}$ & 27 \\
Zero-crossing derivative spectrophotometry & $1.13 \times 10^{-6} \mathrm{M}(0.33 \mu \mathrm{g} / \mathrm{mL})$ & 29 \\
Ratio spectra derivative spectrophotometry & $2.23 \times 10^{-6} \mathrm{M}(0.65 \mu \mathrm{g} / \mathrm{mL})$ & 29 \\
Ratio difference spectrophotometry & $1.71 \times 10^{-6} \mathrm{M}(0.50 \mu \mathrm{g} / \mathrm{mL})$ & 29 \\
HPLC-DAD & $2.74 \times 10^{-6} \mathrm{M}(0.80 \mu \mathrm{gL})$ & 29 \\
Voltammetric method & $8.08 \times 10^{-8} \mathrm{M}$ & Present method \\
\hline
\end{tabular}

HPLC: High-performance liquid chromatography, LOD: Limit of detection, LC-MS: Liquid chromatography-mass spectrometry

Table 3: Influence of potential excipients on the voltammetric response of $1.0 \times 10^{-6} \mathrm{M} \mathrm{KTL}$

\begin{tabular}{lll}
\hline $\begin{array}{l}\text { Excipients (1.0 } \mathbf{~ m M})+D r u g \\
\text { KTL }\left(\mathbf{1 . 0} \times \mathbf{1 0}^{-6}\right)\end{array}$ & $\begin{array}{l}\text { Potential } \\
\text { observed (V) }\end{array}$ & $\begin{array}{l}\text { Signal } \\
\text { change (\%) }\end{array}$ \\
\hline Only Ketorolac & 1.280 & 0 \\
Tartaric acid+KTL & 1.271 & -0.703 \\
Citric acid+KTL & 1.255 & -1.95 \\
Glucose+KTL & 1.270 & -0.78 \\
Gum acacia+KTL & 1.314 & 2.65 \\
Lactose+KTL & 1.244 & -2.81 \\
Dextrose+KTL & 1.265 & -1.17 \\
Sucrose+KTL & 1.268 & -0.93 \\
Starch+KTL & 1.276 & -0.31 \\
\hline
\end{tabular}

Table 4: Analysis of KTL tablet by DPV and recovery studies

\begin{tabular}{ll}
\hline Ketorol (10 $\mathbf{~ m g})$ & DPV \\
\hline Labeled claim (mg) & 10.00 \\
Amount found (mg) & 9.981 \\
RSD (\%) & 01.35 \\
Bias (\%) & -00.19 \\
Added (mg) & 03.00 \\
Found (mg) & 02.89 \\
Recovered (\%) & 96.63 \\
RSD (\%) & 03.31 \\
Bias (\%) & 03.36 \\
\hline
\end{tabular}

${ }^{a}$ Average of three determinations. DPV: Differential pulse voltammetry,

RSD: Relative standard deviation

peak 2, respectively, and $\mathrm{E}^{0^{\prime}}$ were 0.992 and 1.326 , respectively. From the above, calculated $\mathrm{k}^{0}$ values were 140.73 /s and $269.63 / \mathrm{s}$.

\section{Electro-oxidation mechanism}

Exact oxidation mechanism was not determined for KTL, but some conclusions about the electroactive group can be reached. Two $\mathrm{pK}$ values were reported for KTL, a pK value of 3.5 due to the carboxylic group [25] and another 6.2, due to protonation of the tertiary nitrogen in the pyrrole nucleus, from polarographic determination [26]. As the oxidation peaks were observed till $\mathrm{pH} 7.0$ and after that the peaks were vanishes, it can be concluded that heterocyclic nitrogen is directly involved as the electro-oxidable group. Based on all the experimental results and the reported works [26-28] electro-oxidation mechanism for KTL in the acidic medium can be given as shown in Scheme 2.

\section{Analytical determinations}

Under the optimized experimental conditions, GCE was used for the determination of KTL by means of DPV. DPV is having better resolving power and higher sensitivity than CV. Fig. 4 shows the DPVs of KTL at different concentrations. The results showed that the peak current (I) has a linear relationship with the concentration of KTL in the range of 10.0$350.0 \mu \mathrm{M}$ with the following linear characteristics, which is shown in Fig. 4 inset: $I_{\mathrm{pa}}\left(10^{-5} \mathrm{~A}\right)=340.0 \mathrm{KTL}+3.677\left(\mathrm{R}^{2}=0.987\right)$. In these measurements, a theoretical detection limit $(\mathrm{S} / \mathrm{N}=3)$ of $8.08 \times 10^{-8} \mathrm{M}$ was obtained for KTL.

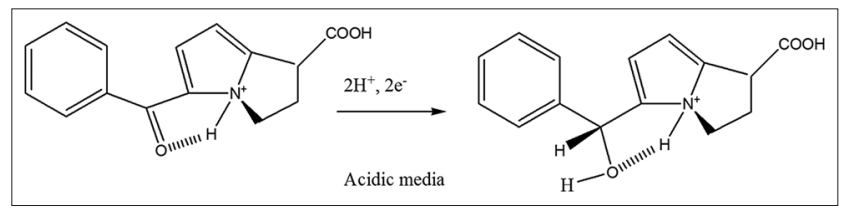

Scheme 2: Probable electro-oxidation mechanism of KTL

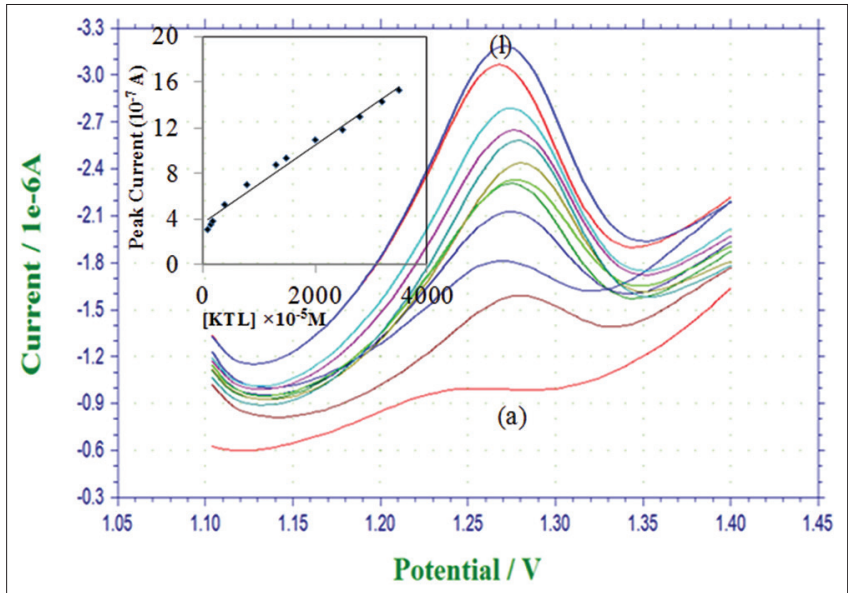

Fig. 4: Differential pulse voltammograms for increasing concentration of KTL at GCE: (a)-(1): $10 \mu \mathrm{M}-350$, inset: Plot of current against the concentration of KTL

As mentioned in the introduction, only a few analytical methods have been reported for the determination of KTL in pharmaceutical or urine samples. Thus, Table 1 shows the analytical parameters obtained in this work and Table 2 shows the parameters obtained using other reported analytical techniques. It can be observed that the analytical parameters obtained, in terms of LOD, herein are better than those based in usual analytical methods [8,25,28-30]. Besides that, HPLC-MS and GC-MS methods require high consumption of organic solvent are timeconsuming for sample pre-treatment, on the other hand, our method requires minimal sample pre-treatment and the instrumentation is inexpensive.

\section{Interference study}

Under the optimized conditions, the influence of various common interferences in pharmaceutical samples for the determination of KTL was studied. 1000-fold Glucose, Gum Acacia, Sucrose, Citric acid, Dextrose, Lactose, Tartaric acid, and Starch had no obvious interference with the current response of KTL (signal change $<10 \%$ ). The results are as shown in Table 3.

\section{Determination of KTL in pharmaceutical preparations}

To demonstrate the electrocatalytic oxidation of KTL in pharmaceutical preparations, we examined this ability in DPV for determination of KTL concentration in tablet sample. 
Table 5: Application of DPV to the determination of KTL in a spiked human urine sample

\begin{tabular}{llllll}
\hline Sample & Added $\left(\times \mathbf{1 0}^{\mathbf{6}} \mathbf{M}\right)$ & Found $^{\mathbf{a}}\left(\times \mathbf{1 0}^{\mathbf{6}} \mathbf{M}\right)$ & Recovery $(\mathbf{\%})$ & RSD $(\mathbf{\%})$ & Bias $(\mathbf{\%})$ \\
\hline 1 & 2 & 1.9786 & 98.93 & 0.524 & -1.07 \\
2 & 5 & 5.016 & 100.32 & 1.608 & 0.32 \\
3 & 6 & 6.203 & 103.38 & 2.625 & 3.38 \\
4 & 8 & 7.954 & 99.425 & 0.778 & -0.575 \\
\hline
\end{tabular}

${ }^{\mathrm{a} A v e r a g e ~ o f ~ t h r e e ~ d e t e r m i n a t i o n s ~}$

The tablets were grounded to powder, dissolved in water and then further diluted so that KTL concentration falls in the range of calibration plot. DPV were then recorded under exactly identical conditions that were employed while recording differential-pulse voltammograms for plotting calibration plot. Based on the repeated DPV responses $(n=3)$ of the diluted analytes and the samples that were spiked with a specified concentration of KTL and using the calibration plot measurements were made of KTL concentrations in the pharmaceutical preparations and the recovery rate of the spiked samples. The results are listed in Table 4 .

\section{Recovery study of KTL in a urine sample}

The developed DPV method for the KTL determination was applied to urine samples. The recoveries from urine were measured by spiking drug-free urine with known amounts of KTL. A quantitative analysis can be carried out by adding the standard solution of KTL into the detection system of urine samples. The calibration graph was used for the determination of spiked KTL in urine samples. The detection results of four urine samples obtained with recovery percentage and RSD are listed in Table 5.

\section{Repeatability and reproducibility of the electrode}

The precision of the method was evaluated by repeating five experiments on the same day and in the same standard condition (repeatability) and over 2 days from the different standard solutions (reproducibility). For these studies, $1.0 \times 10^{-6} \mathrm{M}$ KTL standard solution was used. The corresponding RSD of the peak current of $2.49 \%$ and $2.44 \%$ confirms that the electrode has good repeatability and reproducibility.

\section{CONCLUSIONS}

In this study, the voltammetric determination of KTL is carried out by GCE in a phosphate buffer solution of pH 3.8. pH effects showed the role of proton transfer in the electrochemical process. Effect of potential scan rate was examined, and the results show that the electrochemical process is diffusion controlled. The number of electrons transferred during the process was calculated. Under the optimum condition, KTL shows a linear response in the concentration range from 10 to $350 \mu \mathrm{M}$ and a detection limit of $8.08 \times 10^{-8} \mathrm{M}$, besides presenting good intra- and inter-day repeatability. The method has been successfully applied to the determination of KTL in pharmaceutical samples and recovery study in urine sample successively.

\section{ACKNOWLEDGMENTS}

The authors are grateful to the VGST, Government of Karnataka, Bangalore for the financial assistance under K-FIST programme (GRD251: 2013-2015).

\section{AUTHOR'S CONTRIBUTIONS}

Author Rohini M. Hanabaratti contributed substantially toward the study starting from literature survey, the conception of the problem, its design, data collection, optimization of the experimental conditions, and conduct of experiments. Author Jayant I. Gowda involved in analysis, interpretation of data, preparing of graphs, manuscript writing. Suresh M. Tuwar involved in writing the manuscript, editing, and finalized findings.

\section{CONFLICTS OF INTEREST}

Authors declare no conflicts of interest.

\section{REFERENCES}

1. Zhao Y, Gao Y, Zhan D, Liu H, Zhao Q, Kou Y, et al. Selective detection of dopamine in the presence of ascorbic acid and uric acid by a carbon nanotubes-ionic liquid gel modified electrode. Talanta 2005;66:51-7.

2. Gabbot DA, Cohen AM, Mayor AH, Niemiro LA, Thomas TA. Selective detection of dopamine in the presence of ascorbic acid and uric acid by a carbon nanotubes-ionic liquid gel modified electrode. Eur J Anaesth 1997;14:610-5.

3. Lenz H, Raeder J. Comparison of etoricoxib vs. Ketorolac in postoperative pain relief. Acta Anaesthesiol Scand 2008;52:1278-84.

4. Attar M, Schiffman R, Borbridge L, Farnes Q, Welty D. Ocular pharmacokinetics of $0.45 \%$ ketorolac tromethamine. Clin Ophthalmol 2010;4:1403-8.

5. Devarajan PV, Gore SP, Chavan SV. HPTLC determination of ketorolac tromethamine. J Pharm Biomed Anal 2000;22:679-83.

6. Salaris M, Nieddu M, Rubattu N, Testa C, Luongo E, Rimoli MG, et al. Acid and base degraded products of ketorolac. JPharmBiomedAnal2010; $52: 320-2$.

7. $\mathrm{Gu}$ L, Chiang $\mathrm{H}$, Johnson $\mathrm{D}$. Light degradation of ketorolac tromethamine. Int J Pharm 1998;41:105-13.

8. Sunil G, Jambulingam M, Thangadurai SA, Kamalakannan D, Sundaraganapathy R, Jothimanivannan C. Development and validation of ketorolac tromethamine in eye drop formulation by RP-HPLC method. Arabian J Chem 2017;10:S928-35.

9. Razzaq SN, Ashfaq M, Khan U, Mariam I. Development and validation of Ketorolac Tromethamine in eye drop formulation by RP-HPLC method. Anal Methods 2012;7:2121-6.

10. Sane RT, Tirodkar VB, Desai AJ, Patel MK, Kulkarni UD. Determination of Ketorolac tromethamine. Indian Drugs 1992;29:489-93.

11. Demircan S, Sayin F, Basci NE, Unlu N, Kir S. Determination of ketorolac tromethamine in human eye samples by HPLC with photo diode-array detection. Chromatographia 2007;66:S135-9.

12. Logan BK, Friel PN, Peterson KL, Predmore DB. Analysis of ketorolac in postmortem blood. J Anal Toxicol 1995;19:61-4.

13. Chaudhary RS, Gangwal SS, Jindal KC, Khanna S. Reversed-phase high-performance liquid chromatography of ketorolac and its application to bioequivalence studies in human serum. J Chromatogr 1993; 614:180-4

14. Wu AT, Massey IJ. Simultaneous determination of ketorolac and its hydroxylated metabolite in plasma by high-performance liquid chromatography. J Chromatogr 1990;534:241-6.

15. Kamath BV, Shivram K, Shah AC. Determination of diclofenac sodium, famotidine and ketorolac tromethamine by flow injection analysis using dichloronitrophenol. J Pharm Biomed Anal 1994;12:343-6.

16. Rezaei B, Zare ZM. Modified glassy carbon electrode with multiwall carbon nanotubes as a voltammetric sensor for determination of leucine in biological and pharmaceutical samples. Anal Lett 2008;41:2267-86.

17. Huang L, Bu L, Zhao F, Zeng B. Voltammetric behavior of ethopropazine and the influence of sodium dodecylsulfate on its accumulation on gold electrodes. J Solid State Electrochem 2004;8:976-81.

18. Ivandini TA, Sarada BV, Terashima C, Rao TN, Tryk DA, Ishiguro H, et al. Electrochemical detection of tricyclic antidepressant drugs by HPLC using highly boron-doped diamond electrodes. J Electroanal Chem 2002;521:117-26.

19. Kissinger PT, Heineman WR, Laboratory Techniques in Electroanalytical Chemistry. $2^{\text {nd }}$ ed. New York: Marcel Dekker; 1996.

20. Giselle NC, Christiana AP, Karen W, Noemi N. Simultaneous determination of sulfamethoxazole and trimethoprim in pharmaceutical formulations by square wave voltammetry. Int J Pharm Pharm Sci 2014; $6: 438-42$.

21. Gosser DK. Cyclic Voltammetry: Simulation and Analysis of Reaction Mechanisms. New York: Vancouver Coastal Health; 1993. p. 43.

22. Hassan AM, Hanan ME, Amany MF. Electrochemical and chemometric determination of dorzolamide and timolol in eye drops using modified multiwall carbon nanotube electrode. Int J Pharm Pharm Sci 2017; 
19:43-50

23. Laviron E. General expression of the linear potential sweep voltammogram in the case of diffusionless electrochemical systems. J Electroanal Chem 1979;101:19-28.

24. Wu Y, Ji X, Hu S. Studies on electrochemical oxidation of azithromycin and its interaction with bovine serum albumin. Bioelectrochemistry 2004; 64:91-7.

25. Gu L, Strickley RG. Preformulation salt selection. Physical property comparisons of the tris (hydroxymethyl)aminomethane (THAM) salts of four analgesic/antiinflammatory agents with the sodium salts and the free acids. Pharm Res 1987;4:255-7.

26. Moses GS, Kumar MS, Ramachandraiah A, Roa KM. Spectral and electrochemical investigations of ketorolac tromethamine. Ind J Chem 2003;42B:159-65.
27. Sturm JC, Canelo H, Nuñez-Vergara LJ, Squella JA. Voltammetric study of ketorolac and its differential pulse polarographic determination in pharmaceuticals. Talanta 1997;44:931-7.

28. Squella JA, Lemus I, Sturm JC, Núñez-Vergara LJ, Voltammetric behaviour of ketorolac and its HPLC-EC determination in tablets. Anal Lett 1997;30:553-64.

29. Tambe VS, Deodhar MN, Prakya V. LC and LC-MS study for simultaneous determination of tramadol hydrochloride and ketorolac tromethamine in bulk and formulation with their major degradation products. B-FOPCU 2016;54:87-97.

30. Belal TS, El-Kafrawy DS, Mahrous MS, Abdel-Khalek MM, AboGharam AH. Validated spectrophotometric and chromatographic methods for simultaneous determination of ketorolac tromethamine and phenylephrine hydrochloride. Ann Pharm Fr 2016;74:267-82. 